\title{
O FUNCIOMANENTO DAS MÁQUINAS DE TORTURA: SOBRE A JUSTIÇA DAS PENAS DE PRISÃO. UMA ANÁLISE A PARTIR DO DOCUMENTÁRIO SEM/PENA
}

\section{THE OPERATION OF TORTURE MACHINES: ABOUT THE JUSTICE OF PRISON SENTENCES. AN ANALYSIS FROM THE DOCUMENTARY "SEM/PENA"}

\begin{abstract}
Camila Cardoso de Mello Prando
Professora Adjunta da Faculdade de Direito da UnB. Tutora do PET-Direito-UnB. Mestre e Doutora pelo PPGD-UFSC, com estágio doutoral no Departamento de História e Teoria do Direito da Università Degli Studi di Firenze.
\end{abstract} camilaprando@gmail.com

\section{RESUMO}

0 texto toma como obra de arte de referência o documentário "Sem Pena", dirigido por Eugenio Puppo. A partir dos sentidos e provocações da obra e apropriando-me metodologicamente das perspectivas psicanalíticas sobre a análise das obras de arte e da perspectiva epistemológica feminista de produção de conhecimento analiso os sentidos não ordinários da pena. Formulo três perguntas determinadas pelos seguintes sentidos da palavra pena: autoria, escrita dos letrados e dó. As discussões que seguem a cada uma das perguntas servem para compreender a possibilidade de produção de justiça - no sentido desenvolvido por Derrida - nas decisões que determinam as penas de prisão.

Palavras-chave: Epistemologia Feminista; Prisão; Justiça.

\begin{abstract}
The documentary "No Penalty", directed by Eugenio Puppo is the artwork reference for this text. The non ordinary senses of penalty are considered under the perspective of senses and provocations presented in the documentary using the methodological appropriation of psychoanalitics perspectives of artwork and the feminist epistemological perspective of knowledge production. I bring here three questions determined by the following meanings of the word penalty: authorship, writing of scholars and pity. The discussions that follow each one of the questions cater for understanding the possibilities for the production of justice- from the point of view of Derrida- in decisions that determine the prison sentences.
\end{abstract}

Keywords: Feminist Epistemology; Prison; Justice;

\section{SUMÁRIO}

INTRODUÇAO; 1 OS SENTIDOS DO DOCUMENTÁRIO “SEM/PENA"; 2 QUE PERGUNTAS AINDA PODEMOS

FAZER SOBRE AS MÁQUINAS DE TORTURA ; 2.1 De quem é a autoria do sistema de moer carnes?; 2.2 Onde estão os efeitos das máquinas de tortura na escrita dos letrados?; 2.3 Sobre dó: há lugar para o enlutamento dos corpos moídos?; CONCLUSÃO; REFERÊNCIAS. 


\section{INTRODUÇÃO}

As prisões no Brasil estão ocupadas atualmente por 607.731 presos e presas em estabelecimentos que possuem ao todo 376.669 vagas. De 2000 a 2014 a população penitenciária cresceu $161 \%$, dez vezes mais do que a população brasileira. A maior parte das pessoas presas é negra, jovem e de baixa escolaridade. $41 \%$ delas estão presas sem condenação. ${ }^{1}$

Eugenio Puppo, na direção do documentário "Sem Pena", narra este cenário com os recursos da arte: sons, imagens, testemunhos, falas, que juntos compõem um emaranhado de sentidos. São esses sentidos da obra em diálogo com os sentidos de minha trajetória como pesquisadora que dão lugar às discussões sobre a prisão na escritura deste texto.

A abordagem psicanalítica das obras de arte e as perspectivas da epistemologia feminista são o substrato teórico-metodológico para o uso da obra cinematográfica na produção das reflexões aqui propostas.

Sigo a pista de três perguntas organizadas a partir dos sentidos não ordinários da pena: de quem é a autoria do sistema de moer carnes?; onde estão os feitos das máquinas de tortura na escrita dos letrados?; Há lugar para o enlutamento dos corpos moídos?. As discussões provocadas pelas perguntas encaminham o texto para uma análise das possibilidades de justiça, no sentido atribuído por Derrida, às penas de prisão.

\section{OS SENTIDOS DO DOCUMENTÁRIO “SEM/PENA”}

O documentário Sem/Pena ${ }^{2}$, dirigido por Eugenio Puppo e lançado em 2014 será a obra cinematográfica tomada como ponto de partida para as reflexões sobre o funcionamento das prisões no contexto brasileiro. A demarcação geográfica é ampla, as singularidades e as microrelações que habitam os espaços dos muros também.

Há um muro a separar os mundos, mas é um muro paradoxalmente delimitador na sua visibilidade e poroso em sua textura. Ao mesmo tempo em que o muro invisibiza e garante o

\footnotetext{
${ }^{1}$ MINISTÉRIO DA JUSTIÇA. Departamento Penitenciário (DEPEN). Levantamento Nacional de Informações Penitenciárias. Brasília, junho, 2014.

2 PUPPO, Eugenio. Sem Pena. Direção de Eugenio Puppo, Heco Produções, São Paulo, 2014.
} 
silêncio sobre a existência das máquinas de tortura ele também permite o trânsito de pessoas e de poderes em suas diversas posicionalidades. Um trânsito que opera a circulação desigual de dor e privilégios entre os personagens do encarceramento, dos mundos de dentro e fora.

0 diretor se utiliza da estratégia de reproduzir as vozes sem rostos, promovendo um quebra-cabeças em torno dos vários lugares das falas. Isto produz um efeito potente na medida em que o repertório de interpretações sobre as diversas falas (tanto as análises quanto os testemunhos) acaba por esbarrar no limite da ausência da corporalidade. Não se sabe sobre as roupas, sobre as cores, sobre os sinais que portam os corpos, embora saiba-se mais do que a leitura de um texto escrito. Os signos que carregam as palavras faladas e ouvidas delimitam lugares, mas menos do que os corpos trariam à cena.

Enquanto falam os testemunhos e as análises, imagens parciais, despedaçadas, dão notícias das pessoas que habitam os muros de fora e de dentro. Pés, braços, caminhares, gestos. Um recurso que se aproxima à metonímia na gramática. Essas imagens oferecem a experiência em se tentar, novamente, acessar um quebra-cabeça em busca de algum sentido. Agora não mais dos lugares de quem fala, mas sim das pertenças daqueles pedaços de corpos que perambulam.

A estratégia das vozes sem corpos e dos corpos em pedaços é interrompida pela primeira vez quando a câmera mostra por inteiro os meninos negros à frente da Faculdade de Direito. Não são meninos atrás de muros visíveis que objetivamente o filme quer captar. Mas a arquitetura imponente da faculdade e os meninos na frente também falam de muros, estes nem tão opacos e muito pouco porosos.

A trilha sonora do filme tem seu lugar na aproximação às sensações do aprisionamento. Sons que se assemelham ao fechamento das grades, aos ecos de dentro, à abertura das portas se reúnem às imagens e chegam perto de tocar o telespectador com sentidos que não estão contidos nas falas sem rosto.

Este conjunto de imagens, sons e falas sem rostos será o ponto de partida para o objetivo do texto: explorar os sentidos do aprisionamento. A obra cinematográfica não será o objeto de interpretação. Seguindo a perspectiva da psicanálise e da teoria da arte de DidiHuberman $^{3}$, a obra será aquela que ensina e de onde se apreendem pistas para abertura do

${ }^{3}$ DIDI-HUBERMAN, Georges. O que vemos, o que nos olha. Trad. Paulo Neves. São Paulo: Ed. 34, 1998. 
saber. A obra se relaciona com o "intérprete" não como objeto de contemplação, mas como chamado à experiência. ${ }^{4}$

Explorar os sentidos do aprisionamento a partir dos sentidos despertos pela obra é também uma forma de dialogar com a tarefa das teorias feministas de questionar a epistemologia ocidental moderna e sua ciência androcêntrica determinada a partir de experiências masculinas, brancas e heterossexuais e pautada na perspectiva da razão dicotomicamente separada da emoção.

Para Sandra Harding ${ }^{5}$ um dos projetos das teóricas feministas é tratar da relação e conformação entre o mundo da produção da ciência moderna e seus pressupostos e o outro mundo a que eu chamo de "sensível".

Naturalmente há um outro mundo - o das emoções, sentimentos, valores políticos, o do inconsciente individual e coletivo, dos eventos sociais e históricos explorados nos romances, teatro, poesia, música e arte em geral, e o mundo no qual passamos a maior parte de nossas horas de sonho e vigília sob a constante ameaça de reorganização pela racionalidade científica. Um dos projetos das feministas teóricas é revelar as relações entre esses dois mundos - como cada um modela e informa o outro. ${ }^{6}$

Seguirei neste ensaio a perspectiva psicanalítica do lugar das obras de arte no processo de produção do saber e a perspectiva das teorias feministas da conformação e dimensionamento da relação entre os "dois mundos”, o da racionalidade científica e outros modos sensíveis de conhecer.

\section{QUE PERGUNTAS AINDA PODEMOS FAZER SOBRE AS MÁQUINAS DE TORTURA?}

A visibilidade às violências produzidas dentro dos muros das prisões ganha espaço quando se conta sobre os episódios do Complexo Penitenciário de Pedrinhas, em São Luis do

\footnotetext{
4 Borges trata desta contraposição contemplação versus experiência ao analisar a proposta de interpretação de Lacan e aproximá-la da obra de arte contemporânea, em especial do dadaísmo. (BORGES, Sonia. Quem tem medo do ready-made?: Psicanálise, interpretação e arte contemporânea. Stylus, Rio de Janeiro , n. 25, nov. 2012. Disponível em <http:// pepsic.bvsalud.org/scielo.php?script=sci_arttext\&pid=S1676-

157X2012000200006\&lng=pt\&nrm=iso>. Acesso em 04 ago. 2015).

${ }_{5}^{5}$ HARDING, Sandra. A instabilidade das categorias analíticas na teoria feminista. Revista de Estudos Feministas, Florianópolis, v.1, n. 1, p.7-31, 1993.

${ }^{6}$ Ibidem, p.12.
} 
Maranhão; do Presídio Anibal Bruno, em Recife; do “Urso Branco", em Porto Velho. E outros. Nessas ocasiões a narrativa sobre o que há de morte e violação no sistema prisional aparece com a força das imagens veiculadas e dos mortos contabilizados.

As inspeções que têm sido realizadas nas instituições por parte do organismos dos Estado como o Ministério Público e mais recentemente o Mecanismo Nacional de Prevenção e Combate à Tortura, dão notícias dos números registrados de mortes, homicídios, presos feridos, sanções arbitrárias, privação de comida, humilhações.

Os números são impactantes e norteiam o desenvolvimento de políticas, mas permanecem no campo da impessoalidade, no nosso imaginário do que é possível descartar. São dados escritos no masculino. As perguntas, os instrumentos de pesquisa e as referências de resposta são escritas sob uma ótica masculina e heteronormativa. Identidades sexuais diversas e suas torturas no sistema prisional - os casos da violência a transexuais - e o lugar da mulher são não ditos dos dados acima. As questões particulares de higiene, a misoginia, a transfobia e suas torturas são ainda mais silenciosas e começaram apenas recentemente a serem abordadas nos diagnósticos do sistema prisional brasileiro.

Embora os dados sobre os casos comecem mais sistematicamente a ser produzidos, as histórias ainda estão por ser contadas. O documentário Sem/Pena abre a perspectiva com as vozes dos testemunhos contados na primeira pessoa e com as imagens despedaçadas que povoam as cenas enquanto os ruídos da prisão se perpetuam na trilha sonora. Estes são recursos de compreensão potentes para uma dimensão do mundo do cárcere mobilizada a partir dos sentidos, que pode informar e conformar um olhar reflexivo.

Assistindo ao documentário Sem Pena me senti provocada a pensar a prisão, que a partir de agora chamarei de máquinas de tortura - porque é desta ordem o lugar do encarceramento como política promovida pelo Estado. E a pensar a prisão a partir dos vários sentidos etimológicos da palavra pena. Para ver se encontro neles rastros para nomear os sentidos invisíveis produzidos diariamente pelas máquinas de moer corpos. Sigo a trilha da obra como janela para outros sentidos e o jogo das palavras como modo de desacomodar o que o uso corrente das palavras esconde. ${ }^{7}$

\footnotetext{
${ }^{7}$ Borges refere-se à passagem de texto inédito de Lacan no qual o psicanalista propõe que o analista "interprete jogando com as palavras, ou seja, de uma forma provocativa que rompa com significados estáveis, que seja capaz de despertar o que o uso corrente do discurso ordinário adormece, evitando-se, assim, engordar o sintoma com significados." (BORGES, Sonia, 2012, p.94)
} 
O Dicionário da Lingua Portuguesa nos diz que há duas origens etimológicas do sentido pena. Uma decorre de uma expressão latina "penna" que significa o órgão que cobre o corpo das aves, mas também "4 0 trabalho de escrita. 5 Os letrados e escritores. (...) 8 Autor, escritor.". 0 outro sentido decorre da expressão latina "poena", e pode significar: "sf (lat poena) 1 Castigo, punição", e também "7 Compaixão, dó, piedade"8.

É possível que o diretor tenha se utilizado desse substantivo como forma de, separando a comunicação entre a preposição "sem” e o substantivo "pena" com um sinal gráfico “/”, sugerir as várias invocações possíveis da sentença: a) sem dó, sem compaixão; e também b) sem pena, sem prisão. Sentença essa sugestiva ao ser barrada por um muro que pode ser o muro do cárcere.

Mas eu quero aqui me apropriar do outro sentido de pena, advinda de sua primeira origem etimológica aqui apontada, e pensar que também é possível entender o substantivo "pena" como "o trabalho da escrita dos letrados" ou como "autoria". A perspectiva é ampliar a indagação sobre a pena, provocada pelo que vai além da obra e pelo que ela me ensina com suas imagens. Mobilizarei os quatro sentidos (autoria, escrita dos letrados, dó e pena) para entender mais sobre o funcionamento das máquinas de tortura e fazer perguntas sobre a pena de prisão.

\section{De quem é a autoria do sistema de moer carnes?}

Uma sequência de agentes e instituições é visibilizada durante as imagens do filme: policiais, agentes carcerários, advogado, promotora, juiz e o sem número de sem nomes sobre os quais recaem o castigo. As imagens nos constrangem a perceber um movimento que parece desordenado, um vai e vem de intervenções e de pessoas que figuram como agentes para o funcionamento da grande máquina da tortura.

Se de um lado os uniformes, as vestimentas, as cores que surgem na tela nos informam sobre as diversas posicionalidades e poderes assimétricos dos personagens nesse cenário de tortura, por outro, em algum momento elas nos confundem a saber quem é quem e nos remetem ao questionamento de entender até que ponto todos eles fazem funcionar as engrenagens às custas do próprio corpo. Muitos com seus corpos já sem vida, outros com um corpo psíquico

\footnotetext{
${ }^{8}$ Pena. MICHAELIS: Dicionario de Português Online. São Paulo: Melhoramentos, disponível em http://michaelis.uol.com.br/moderno/portugues/index. php?lingua=portugues-portugues\&palavra=pena. Acessado em 28 de abril de 2015.
} 
devorado pelo trabalho sem fim e sem sentido. Existem os que são torturados e existem os que torturam. Mas qual o corpo, o nome, o cheiro, a representação dos que torturam? Talvez efeito do aparente caos da administração da máquina de fazer tortura, talvez efeito de um mal arranjado modo de produção burocrático, as responsabilidades se diluem a tal ponto que ninguém é autor do funcionamento da máquina. Se no plano micro, face a face, encontramos o algoz, ao darmos 10 passos atrás e procurarmos entender a autoria da ordem, tudo se mancha.

As vozes sem rosto do filme descrevem um cenário de terror, da parte de quem são os torturados e torturadas, e também da parte dos que dão os 10 passos atrás e que, portanto, dispõem-se a entender um pouco de onde vem e para onde vai essa máquina que tritura corpos. Os dedos invisíveis das falas sem rosto apontam para muitas direções, mas não são capazes de dar nome, corpo e autoria. O que acresce o terror da cena: a máquina de tortura parece não ter autoria.

Afinal, de quem é a autoria? Do juiz que assina a sentença, do gestor da administração que gerencia recursos, do parlamentar que aprova mais cárcere, do agente penitenciário que barganha micropoderes, do advogado que se ocupa das boas relações mais do que do condenado, do promotor que pede mais e mais punição? Ou, quem sabe, como hoje se gosta de explicar, dos próprios corpos moídos que desafiam, só eles, uma lei não dita e não escrita - a lei da ordem desigual, racista e letal?

Para além do discurso neoliberal que atribui com facilidade a responsabilidade da tortura ao próprio torturado que não batalhou para viver uma vida "fora do crime", entendido exclusivamente como tráfico ou violações contra o patrimônio -, temos alguma tradição teórica que nos explica os efeitos da desresponsabilização no processo da matança do outro.

Bauman, por exemplo, em Holocausto e Modernidade, aponta para a racionalidade instrumental e a burocracia que, quando isoladas de qualquer outra racionalidade, tendem a produzir um processo de desresponsabilização que põe em movimento um Estado que calcula, planeja e exclui e se articula a partir da divisão, hierarquização de tarefas e uma responsabilidade moral substituída pela técnica. ${ }^{10}$

Ginzburg, em Olhos de Madeira, com a pergunta "Você mataria um mandarim chinês desconhecido se thes oferecessem um bom dinheiro?", produz um ensaio no qual aborda os

\footnotetext{
${ }^{9}$ Sobre a relação entre neoliberalismo e as novas estratégias políticas punitivas ver a tese de WACQUANT, Loic. As prisões da miseria. Rio de Janeiro: Jorge Zahar, 2001; Punir os pobres: a nova gestão da miseria nos EUA. 3 ed. Rio de Janeiro: Revan/ICC, 2007; Marginality, ethnicity and penality in the neoliberal city. An analitic cartography. Ethnic and racial studies, Guildfort, vol.37, n.10, 2014.

${ }^{10}$ BAUMAN, Zygmunt. Holocausto e Modernidade. Rio de Janeiro: Jorge Zahar, 1998.
} 
efeitos da distância engendrada pelas distinções do mundo ocidental entre "nós" e "eles" e suas consequências morais trágicas. ${ }^{11}$

Da parte das teorias críticas criminológicas e das explicações macro muito cuidado também é importante para entender a ordem da autoria da máquina de moer corpos. 0 capitalismo e a luta de classes podem ser recursos para silenciar outras estruturas de violência, especialmente no Brasil em que o campo criminológico até o momento foi pouco atravessado pela discussão racial ${ }^{12}$.

\subsection{Onde estão os efeitos das máquinas de tortura na escrita dos letrados?}

A máquina de tortura se vale da oralidade sem rosto e das imagens metonímicas para se fazer ver. Os labirintos e corredores acumulados por papéis não nos dão notícias de que lá possamos encontrar a escrita da tortura. Os papéis são levados sem direção, guardados sem propósito e manejados sem empatia pelos personagens que fazem a máquina de tortura funcionar. Do mesmo modo com que as pernas dos torturados vagam sem sentido pelos corredores das celas e pelo pátio quadrado. Entre eles há um muro, mas é um muro que não foi escrito na escritura dos letrados. É um muro escrito com o silêncio e a carne produzida pela máquina de tortura. As palavras escritas nos papéis que se acumulam nos corredores falam de artigos de lei, de ordem pública, de periculosidades e de critérios de necessidade que sobrepujam regras. Mas não falam da cor dos corpos, não falam sobre o que acontece nas carnes que perambulam por dentro dos muros. 0 que acresce o terror da cena: a máquina de tortura não está na escrita dos letrados. Para fora dos muros a ausência da escrita dos letrados opera uma mágica: não existe máquina de tortura no mundo. Os rostos que aparecem quando a câmera espreita a Faculdade de Direito são bustos mudos de homens brancos. Os rostos que surgem no filme como exceção às vozes sem rosto são bustos mudos no pátio onde se barganham poderes no funcionamento da máquina de tortura.

Entre os poderes que fazem a máquina funcionar estão as decisões provenientes do Poder Judiciário. Cabe perguntar com especial atenção neste ensaio especialmente escrito para

\footnotetext{
${ }^{11}$ GINZBURG, Carlo. Olhos de Madeira. São Paulo: Cia das Letras, 2001.

12 Textos do campo criminológico que pontuam a discussão: DUARTE, Evandro Piza. Criminologia e Racismo. Curitiba, Juruá, 2002; FLAUZINA, Ana Luiza. Corpo negro caído no chão: o sistema penal e o projeto genocida do Estado brasileiro. Rio de Janeiro: Contraponto editora, 2008.
} 
circular no campo do direito, qual a escrita da tortura no mundo dos juristas, os letrados antigos da República.

Escolho como caso inicial para problematizar o silêncio dos juristas na escritura da tortura a decisão do Recurso Extraordinário 453.000, originário do Rio Grande do Sul, resultado da provocação ao Supremo Tribunal Federal (STF), chamado para decidir sobre a inconstitucionalidade da reincidência como circunstância agravante na fixação da pena. ${ }^{13}$

A decisão final promovida em 04 de abril de 2013 considerou por unanimidade constitucional o uso da circunstância reincidência como motivo de aumento da pena. Em resposta ao argumento do condenado apresentado em Recurso Extraordinário de que a reincidência apenaria duas vezes o indivíduo pelo mesmo crime e que obstaria a aplicação constitucional do princípio da individualização da pena, o STF entendeu que não há possibilidade de se tratar de modo igual um réu que cometeu crime e voltou a delinquir e os demais réus tecnicamente primários. Também por unanimidade o STF aplicou à tese repercussão geral e decidiu, com voto vencido pelo Ministro Marco Aurélio, que a partir daquele momento as decisões poderão ser tomadas monocraticamente pelos relatores.

Os argumentos mobilizados nos votos dos ministros passaram por referências à tradição histórica e internacional do uso da reincidência como circunstância de análise da pena; pela perspectiva do impacto da análise de inconstitucionalidade de reincidência nos demais institutos da pena, como o livramento condicional, a suspensão condicional da pena, a substituição da privativa de liberdade pela restritiva de direito, a determinação inicial e progressão de regime da pena privativa de liberdade, a causa de diminuição de pena prevista na Lei de Entorpecentes (11.343/2006); pelo princípio da igualdade supostamente fundado no tratamento desigual a ser dado entre os que voltam a delinquir e os demais; pelas funções da pena de ressocialização e intimidação; pela garantia da ordem social e pela defesa da sociedade.

Com exceção do voto proferido pelo Ministro Gilmar Mendes, nos demais não houve alusão ao modo de funcionamento das prisões - pena preponderante no sistema de justiça brasileiro -, de forma que o fundamento dos votos dos Ministros passava por uma aceitação das funções declaradas da pena de prisão, tais como ressocialização e intimidação. ${ }^{14}$ Daí concluíam

13 Esta decisão é uma das que serão objeto de análise da Pesquisa Intitulada "Encarceramento, democracia e Supremo Tribunal Federal", submetido ao CNPq. O objetivo da pesquisa é estudar as decisões do Supremo Tribunal Federal com impacto no campo penal e processual penal e seus reflexos no processo de encarceramento em massa.

${ }^{14}$ Sobre funções declaradas e latentes da pena no controle penal moderno ver ANDRADE, Vera Regina Pereira. Ilusão de segurança jurídica. Do controle da violência à violência do controle penal. Porto Alegre: 
que alguém que já tenha sido apenado e ainda assim não tenha compreendido sobre a necessidade de atuar de modo a não violar a lei penal, deve receber uma punição mais grave. A exclusão fundamental e que mina de modo absoluto os argumentos presentes nos votos é a da realidade do funcionamento das chamadas prisões que são, antes, máquinas de torturar corpos.

Como é possível sustentar a isonomia entre os que são encarcerados e os que nunca foram, determinando maior repressividade aos primeiros? Que ordem de inversão é esta que só pode ser retoricamente sustentada caso ignore intencionalmente o modo de execução das penas de prisão? Como se justificam os argumentos sustentados naqueles votos senão pela solene ausência das máquinas de tortura no mundo dos letrados, e sua "sempre ilustrada maioria" - na fala de Marco Aurélio referindo-se aos demais Ministros do STF - ${ }^{15}$

O Ministro Marco Aurélio silenciou em sua escritura qualquer referência às funções reais da pena de prisão, tornando possível enunciar a discutível e seletiva tese penal do homem médio em sua perspectiva de realização dos valores gregários e solidários por meio da pena como advertência, seguindo mesmo o fundamento da “ordem natural das coisas" em pleno direito produzido no século XXI.

Está-se diante de fator de discriminação que se mostra razoável, seguindo a ordem natural das coisas. Repito que se leva em conta o perfil do réu, percebendo-se a necessidade de maior apenação, consideradas a pena mínima e a máxima do tipo, porque voltou a delinquir apesar da condenação havida, no que esta deveria ser tomada como um alerta, uma advertência maior quanto à necessidade de adoção de postura própria ao homem médio, ao cidadão integrado à vida gregária e solidário aos semelhantes. ${ }^{16}$ (grifo nosso).

\footnotetext{
Livraria do Advogado, 1997; BARATTA, Alessandro. Criminologia Crítica e Crítica do Direito Penal. Introdução à sociologia do Direito Penal. 2 ed. Rio de Janeiro: Revan, 1999.

${ }_{15}$ Para além de ignorar o modo de execução da pena de prisão este é um argumento que também desconhece um dos dados mais contundentes do funcionamentos das agências de controle penal: a seletividade punitiva. A vulnerabilidade a que estão expostos determinados grupos sociais, cujo marcador estrutural é a distinção racial, determina que o encarceramento esteja concentrado sobre estes grupos, de modo que o dado sobre a reincidência não revela quem são aqueles que mais violam lei penal, mas antes aqueles que mais são criminalizados pelas agências de controle. Sobre seletividade penal, suas referências empíricas e o tratamento teórico cf. MINISTÉRIO DA JUSTIÇA. Departamento Penitenciário (DEPEN). Levantamento Nacional de Informações Penitenciárias. Brasília, junho, 2014, BARATTA, Alessandro, 1999. Sobre propostas dogmáticas de reconhecimento da seletividade na construção de institutos dogmáticos, cf. o instituto da culpabilidade por vulnerabilidade, ZAFFARONI, Raul Eugenio. Culpabilidade por vulnerabilidade. Discursos Sediciosos. N.14, p.32-44, 2004; a co-culpabilidade como circunstância atenuante, SANTOS, Juarez Cirino dos. A moderna teoria do fato punível. 2 ed. Rio de Janeiro: Revan, 2002.

${ }_{16}$ Voto proferido pelo Ministro Marco Aurélio. STF. RE 453.000 - RS, Relator: MARCO AURÉLIO, Data de Julgamento: 04/04/2013, Tribunal Pleno, Data de Publicação: DJe-194 DIVULG 02-10-2013 PUBLIC 03-102013, p.4.
} 
Durante seu voto, o Ministro apenas resvalou no tema da funcionamento das prisões e do sistema de justiça penal por meio da referência à discussão dogmática da inconstitucionalidade da reincidência, fazendo menção a Silva Franco, Zaffaroni, Pierangeli, Dotti, Cirino dos Santos e - que é fundada no reconhecimento da seletividade e dos efeitos do encarceramento. Ironicamente tal referência foi trazida ao voto para em seguida apagá-la, na medida em que se referiu à não adesão do STF a esta tese em julgados anteriores, reconhecendo apenas "a importância acadêmica da discussão". ${ }^{17}$

Mais do que o silenciamento na escrita dos letrados, o voto registra a despreocupação política com a produção do encarceramento em massa, responsável pelo agravamento das condições das máquinas de torturas. Citando o caso das decisões relativas à Lei de Drogas (inconstitucionalidade do impedimento em abstrato da liberdade provisória, do início de pena em regime fechado e da impossibilidade de substituição por restritiva de direitos), no qual o entendimento do Ministro foi vencido, Marco Aurélio revela sua preocupação com o crime de tráfico - responsável pelo aumento exponencial das taxas de encarceramento - e seu "inexcedível malefício"18. Para o Ministro, os posicionamentos que favoreceram 0 desencarceramento com as declarações de inconstitucionalidade acima podem ser lidos como uma forma de "exacerbação do garantismo penal"19. Para ele o uso deste "garantismo" produz um "desmonte do sistema criminal normativo". ${ }^{20}$

No voto do Ministro é possível reconhecer que o "sistema normativo" não dialoga com a empiria, ao contrário, ele se alimenta de uma retórica da ordem social contra a criminalidade que não é chamada em nenhum momento a demonstrar suas evidências, e que ao mesmo tempo promove o aumento do encarceramento e a precarização das máquinas de tortura com sua superlotação.

A Ministra Rosa Weber desconsidera em seu voto não só as condições do encarceramento como também os efeitos promovidos pelas máquinas de tortura no processo de distanciamento social das pessoas encarceradas, e considera - ao estilo das explicações neoliberais - a responsabilidade que recai absolutamente sobre um suposto indivíduo abstrato, igual e livre que

\footnotetext{
17 Ibidem, p. 5.

18 Ibidem, p. 6.

${ }^{19}$ Ibidem, p. 7.

20 Ibidem, p. 7.
} 
escolhe permanecer no mundo do crime e com isto demonstra "maior propensão à prática delitiva e que o apenamento anterior não foi suficiente para prevenir e reprimir o crime". ${ }^{21}$

Esse argumento também é repetido no voto do Ministro Luiz Fux, ao qual ele acrescenta que a tese apresentada por Juarez Cirino é uma tese “que escapa ao âmbito jurídico"22, já que não seria dado ao poder judiciário saber se a reincidência se deve a um fator da personalidade e aqui ele recupera a insustentável tese lombrosiana do criminoso nato - ou ao funcionamento do sistema carcerário. Em seu voto o Ministro enuncia um campo do jurídico que deve estar desconectado da empiria e suas produções de evidências acerca do real funcionamento das máquinas de tortura, resolvendo tal equação por meio da crença (jurídica?) de que o instituto da reincidência é um instrumento para reforçar freios de inibição no condenado.

A Ministra Carmen Lucia e o Ministro Ricardo Lewandowski seguem o argumento da constitucionalidade da reincidência fundada na maior reprovabilidade sobre os que voltam a delinquir e na pena como ação preventiva, visto o novo crime como expressão de vontade de um indivíduo abstrato, universal, livre e igual e ignorando de modo solene o modo de execução das penas, seus efeitos e a própria vulnerabilidade destes "reincidentes" ao processo criminalizador. Nada disto toca o repertório argumentativo na decisão dos Ministros que, sob pretexto de não se utilizarem de argumentos não jurídicos ou de não se embrenharem em debates acadêmicos, fundam suas decisões numa crença na existência do indivíduo da antropologia liberal ${ }^{23}$ e no efeito preventivo da pena - efeito este também creditado à pena no voto do Ministro Joaquim Barbosa - que nada tem a ver com as máquinas de torturar corpos.

O Ministro Gilmar Mendes, por sua vez, ensaiou registrar a tortura na escrita dos letrados $^{24}$, mas logo depois sem maiores explicações não deu a sua avaliação maiores consequências ao campo da decisão jurídica.

\footnotetext{
${ }^{21}$ Voto proferido pela Ministra Rosa Weber. STF. RE 453.000 - RS, Relator: MARCO AURÉLIO, Data de Julgamento: 04/04/2013, Tribunal Pleno, Data de Publicação: DJe-194 DIVULG 02-10-2013 PUBLIC 03-102013, p. 3.

22 Voto proferido pelo Ministro Luiz Fux. STF. RE 453.000 - RS, Relator: MARCO AURÉLIO, Data de Julgamento: 04/04/2013, Tribunal Pleno, Data de Publicação: DJe-194 DIVULG 02-10-2013 PUBLIC 03-102013, p. 19.

${ }^{23}$ SANTORO, Emilio. Autonomia individuale, libertà e diritti. Una critica dell'antropologia liberale. Pisa: ETS, 1999.

${ }^{24}$ Dois votos proferidos pelo Ministro Roberto Barroso em ações mais recentes junto ao STF também trazem à questão o registro da tortura na escrita dos letrados. Mas que merecem ainda serem compreendidos sistematicamente e na sua integração aos efeitos jurídicos atribuídos a este reconhecimento. No primeiro voto, em ação referente a pedido de indenização a preso em RE 580252 MS, Barroso reconheceu as condições intoleráveis de funcionamento das máquinas de tortura, mas apesar disto entendeu que seria melhor para o requerente e para o Estado que ao invés de indenização lhe fosse
} 
No nosso caso, que me parece que a discussão é importante, e suscita, diante dos índices que se indicam de reincidência, é a falência do próprio modelo penal prisional. Essa é a questão que eu acho que o debate suscita, destaca e chama atenção. Acho que é importante que se discuta e que se considere que, em princípio, as nossas instituições prisionais, elas não dispõem de condições minimamente adequadas de ressocialização. $E$, por isso, nós temos, em alguns Estados, segundo índices que talvez não sejam precisos, um grau de reincidência que chega até $80 \%$, segundo dados que correm por aí. (...) De modo que, acho que o debate, no atual estágio, é importante para que nós pensemos criticamente a questão da efetividade ou da inefetividade do modelo repressivo prisional. Acompanho o Relator. ${ }^{25}$

Afinal, qual a pena que está inscrita na escritura dos juristas? Que campo jurídico é este que não pode ter contato com o que nos conta a empiria?

A escrita dos juristas dá as costas às máquinas de tortura. E se não bastasse, põe em movimento mais e mais suas máquinas de moer carne. Dogmática, para os juristas, prescinde de empiria, é apenas uma invenção no mundo do dever ser aos moldes dos influxos neokantianos, que coincidentemente mantém a ordem desigual e letal e seus próprios privilégios.

\subsection{Sobre dó: há um lugar para o enlutamento dos corpos moídos?}

Dó é um dos sentidos de pena e pode significar em sua leitura mais corrente "compaixão lástima, comiseração", mas também pode ter o sentido de “luto”, segundo os dicionários. ${ }^{26}$ Tomo a liberdade de me apropriar desse segundo e esgarçar as possibilidades dos sentidos. A máquina de tortura mói corpos com cor, mói o tempo, mói o movimento, mói os desejos e as possibilidades, e mói, no limite, a carne dos corpos. Ela funciona freneticamente a escolher mais

deferida uma remição de pena. 0 que parece relativizar os direitos da população submetida às máquinas de tortura, que em virtude do reconhecimento de suas condições de funcionamento deveriam ter acesso ao direito à indenização e deveriam ter os efeitos mitigados da pena, e não uma opção entre uma resposta ou outra que revela, talvez o posicionamento pouco reconhecido de seu lugar de acesso à decisões justas quando figura como requerente um preso. No Segundo voto, em que foi vencido, no HC 123.533 -SP, Barroso tratou das condições do aprisionamento e decidiu por uma interpretação restrita à lesividade e desvinculada de características do autor na avaliação do princípio da insignificância. Para construir seu argumento tratou diretamente das condições do sistema prisional brasileiro.

${ }^{25}$ Voto proferido pelo Ministro Gilmar Mendes. STF. RE 453.000 - RS, Relator: MARCO AURÉLIO, Data de Julgamento: 04/04/2013, Tribunal Pleno, Data de Publicação: DJe-194 DIVULG 02-10-2013 PUBLIC 03-102013, p. 2.

26 MICHAELIS: Dicionario de Português Online. São Paulo: Melhoramentos, disponível em: http://michaelis.uol.com.br/moderno/portugues/index.php?lingua=portugues-portugues\&palavra=d\%F3. Acessado em 28 de abril de 2015. 
corpos para alimentar seu funcionamento. Do outro lado os personagens que movimentam a máquina não têm tempo para dar 10 passos atrás e exercitar o estranhamento, ocupados demais que estão em selecionar corpos, promover assinaturas sem autorias, escrever palavras do mundo dos letrados que silenciam a tortura.

Se as imagens da obra nos convocam a perceber o tempo arrastado, moído, confiscado dos torturados, também nos incitam a ver o trabalho de Sísifo dos que arrastam as pedras até a montanha para buscá-las em seguida. Não há tempo para perplexidade, não há tempo para o enlutamento dos corpos moídos.

Há um paradoxo entre os que dispõem de um tempo arrastado mas devastado pela falta de sentido, e um tempo que exige tarefas, carimbos, transporte de papeis, transporte de corpos. A "luta contra o crime" não pode parar.

José, Joana, Luis, Maria são nomes de corpos moídos para os quais não há o tempo do luto. São descartes da "luta contra o crime". Se é possível afirmar que a sensibilidade moderna ou, como afirma Garland "al menos los sectores de la sociedad que influyen en la construcción de políticas"27 - rejeita o castigo na sua forma corporal, o que explica em parte o sucesso das prisões na modernidade penal e a substituição das penas corporais, também não se pode ignorar que esta sensibilidade que supostamente rejeita a violência se constitui de modo fragmentado e seletivo.

Fragmentado porque as políticas de governo estão autorizadas à inflição de dor e violência, desde que sob determinadas formas. A prisão, neste caso, também serve para compreender esta sentença, porque mesmo que as suas condições sejam bem diversas das que encontramos no cenário brasileiro, as evidências dos agudos sofrimentos psíquicos e emocionais existentes sob a forma ascética de "perda da liberdade" são toleradas, em razão também de estarem ocultas do olhar público através dos muros. ${ }^{28}$ Se destacamos as condições da prisão no Brasil constatamos que a tolerância é mais do que uma admissão de políticas que determinam experiências de dor psíquica e emocional, mas de experiências de castigos físicos que atingem a letalidade.

Na política de extermínio, às vezes sequer o muro é necessário para a tolerância existir diante do olhar público. E isto se explica pela segunda característica do que Garland chama de sensibilidade moderna, ela é seletiva, seja porque admite a inflição de sofrimento que "no sea

\footnotetext{
${ }^{27}$ GARLAND, David. Castigo y sociedad moderna. Un studio de teoría social. Buenos Aires: Siglo veintiuno, 1999, p. 282.

${ }^{28}$ Ibidem, p. 283.
} 
imediatamente visible o que no se relacione con 'gente como uno'."29 0 que significa dizer que há tolerâncias que não se adequam ao suposto padrão da sensibilidade moderna quando o castigo físico, a experiência de dor, e mesmo a letalidade não está dirigida a "pessoas comuns". Dois grandes regimes de poder marcam o destino dos corpos e permitem que a tarefa seja fácil e sem grandes repercussões morais e sociais: racismo institucional e patriarcado garantem que José, Joana, Luis e Maria sejam cifras, não sejam nomes. Sejam corpos que não se enlutam.

\section{CONCLUSÃO}

O nome do filme "Sem Pena" barrado pelo muro sugere poucos horizontes. Mas também convoca a subverter o sentido e desfazer o muro; enlutar os corpos caídos; romper com o silêncio da escrita dos letrados, chamar à responsabilidade as autorias ausentes.

É nesse horizonte que por um momento se pode deflagrar algum sentido da justiça no campo do direito. Qualquer decisão do direito que determine o destino de corpos à máquina de tortura, não só tem sua validade e sua legitimidade postas em questão, mas destitui qualquer possibilidade de realização de justiça, daquela justiça que nos fala Derrida, da justiça que não é direito, que é imponderável, indizível, mas que se concretiza sempre como apelo à justiça, e "que exige ser instalada num direito que deve ser posto em ação."30

Não se trata de uma justiça prévia, definida, fundada. Mas sim de um apelo que se faz, dentre outras tarefas, a partir de um questionamento em torno dos limites teóricos e normativos de nossas heranças dos sentidos herdados de justiça. Um questionamento que, segundo Derrida, "só pode ser motivado (...) na exigência de um aumento ou de um suplemento de justiça (...), "31 Trata-se de uma tarefa politicamente motivada, com a intenção de ampliar os sujeitos a quem se endereçam a justiça e como forma de ampliar apelos à justiça, o que nos leva "a denunciar não apenas os limites teóricos, mas também injustiças concretas." ${ }^{32 i}$ José, Joana, Luis, Maria não estão alcançados por uma formulação de justiça ao serem os objetos das máquinas de tortura.

\footnotetext{
${ }^{29}$ Ibidem, p.283.

${ }^{30}$ DERRIDA, Jacques. Força de lei: o pensamento místico da autoridade. São Paulo: Martins Fontes, 2007, p. 43.

31 Ibidem, p. 39.

32 Ibidem, p. 37.
} 
Diante das máquinas de tortura há uma tarefa politicamente irrecusável: incorporar os corpos torturados como corpos vivos. José, Joana, Luis, Maria devem ser sujeitos a quem se endereçam a justiça e de onde se escutam e se protagonizam apelos à justiça.

\section{REFERÊNCIAS}

ANDRADE, Vera Regina Pereira. Ilusão de segurança jurídica. Do controle da violência à violência do controle penal. Porto Alegre: Livraria do Advogado, 1997.

BARATTA, Alessandro. Criminologia Crítica e Crítica do Direito Penal. Introdução à sociologia do Direito Penal. 2 ed. Rio de Janeiro: Revan, 1999.

BAUMAN, Zygmunt. Holocausto e Modernidade. Rio de Janeiro: Jorge Zahar, 1998.

BORGES, Sonia. Quem tem medo do ready-made?: Psicanálise, interpretação e arte contemporânea. Stylus, Rio de Janeiro , n. 25, nov. 2012. Disponível em <http: / / pepsic.bvsalud.org/scielo.php?script=sci_arttext\&pid=S1676157X2012000200006\&lng=pt \&nrm=iso>. Acesso em 04 ago. 2015.

DERRIDA, Jacques. Força de lei: o pensamento místico da autoridade. São Paulo: Martins Fontes, 2007.

DIDI-HUBERMAN, Georges. O que vemos, o que nos olha. Trad. Paulo Neves. São Paulo: Ed. 34, 1998.

DUARTE, Evandro Piza. Criminologia e Racismo. Curitiba, Juruá, 2002.

FLAUZINA, Ana Luiza. Corpo negro caído no chão: o sistema penal e o projeto genocida do Estado brasileiro. Rio de Janeiro: Contraponto editora, 2008.

GARLAND, David. Castigo y sociedad moderna. Un studio de teoría social. Buenos Aires: Siglo veintiuno, 1999.

GINZBURG, Carlo. Olhos de Madeira. São Paulo: Cia das Letras, 2001.

HARDING, Sandra. A instabilidade das categorias analíticas na teoria feminista. Revista de Estudos Feministas, Florianópolis, v.1, n. 1, p.7-31, 1993.

MICHAELIS: Dicionario de Português Online. São Paulo: Melhoramentos, disponível em: http: //michaelis.uol.com.br/moderno/portugues/index.php?lingua=portuguesportugues\&palavra=d\%F3. Acessado em 28 de abril de 2015.

MINISTÉRIO DA JUSTIÇA. Departamento Penitenciário (DEPEN). Levantamento Nacional de Informações Penitenciárias. Brasília, junho, 2014. 
ISSN 1981-3694

(DOI): $10.5902 / 1981369419826$ REVISTA ELETRÔNICA DO CURSD DE

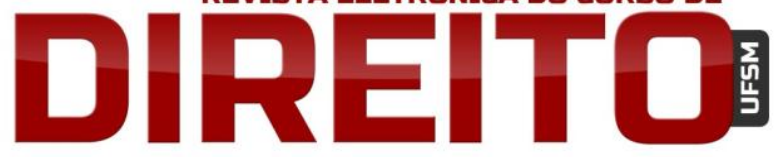

O FUNCIONAMENTO DAS MÁQUINAS DE TORTURA: SOBRE A JUSTIÇA DAS PENAS DE PRISÃO. UMA ANÁLISE A PARTIR DO DOCUMENTÁRIO SEM/PENA

PUPPO, Eugenio. Sem Pena. Direção de Eugenio Puppo, Heco Produções, São Paulo, 2014.

SANTORO, Emilio. Autonomia individuale, libertà e diritti. Una critica dell'antropologia liberale. Pisa: ETS, 1999.

SANTOS, Juarez Cirino dos. A moderna teoria do fato punível. 2 ed. Rio de Janeiro: Revan, 2002.

STF. RE 453.000 - RS, Relator: MARCO AURÉLIO, Data de Julgamento: 04/04/2013, Tribunal Pleno, Data de Publicação: DJe-194 DIVULG 02-10-2013 PUBLIC 03-10-2013.

ZAFFARONI, Raul Eugenio. Culpabilidade por vulnerabilidade. Discursos Sediciosos. N.14, p.3244, 2004.

WACQUANT, Loic. As prisões da miseria. Rio de Janeiro: Jorge Zahar, 2001; 2007; Punir os pobres: a nova gestão da miseria nos EUA. 3 ed. Rio de Janeiro: Revan/ICC, - Marginality, ethnicity and penality in the neoliberal city. An analitic cartography. Ethnic and racial studies, Guildfort, vol.37, n.10, 2014.

Recebido em: 06.10.2015 / Revisões em: 16.10.2015 / Aprovado em: 19.10.2015 